\title{
The Skin Properties of Sites Predisposed to Pressure Ulcers in Bedridden Elderly Patients: A Cross-sectional Study
}

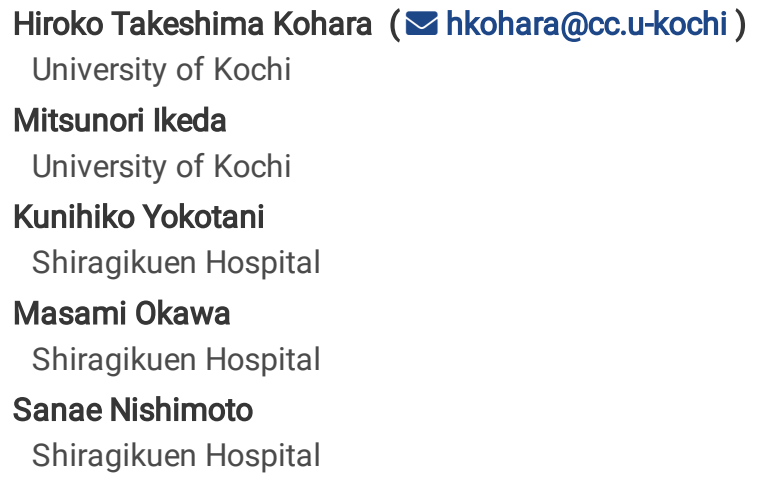

\section{Research article}

Keywords: Epidermal water content, Pressure ulcer, Skin barrier function, Skin elasticity, Skin erythema, Skin surface temperature, Skin thickness

Posted Date: February 14th, 2020

DOI: https://doi.org/10.21203/rs.2.23567/v1

License: (c) (i) This work is licensed under a Creative Commons Attribution 4.0 International License. Read Full License 


\section{Abstract}

Background: Previous studies have not specifically measured skin characteristics at common sites of pressure ulcers in high-risk older patients. Therefore, this study aimed to clarify the physiological skin characteristics at common pressure ulcer sites and their relationship with pressure ulcer risk and demographic/laboratory data in bedridden older Japanese patients.

Methods: Fifty-five older patients (32 female) with a mean age of $82.4 \pm 9.8$ years (range, 61-103 years) in a long-term care facility and 25 female Japanese university students with a mean age of 21.4 \pm 1.3 years (range, 20-22 years) were recruited for the study. Skin surface temperature, epidermal water content, transepidermal water loss (TEWL), skin erythema/redness, skin elasticity, and skin thickness were measured noninvasively and compared between age groups. The sacral and two heel areas were evaluated as they constitute sites predisposed to pressure ulcers, while the mid-to-lower back area was designated as the control site. Additionally, the correlation between demographic/laboratory data and skin physiological indices was determined.

Results: Elderly patients showed a low epidermal water content at both heels (right heel, $14.8 \pm 9.1$ arbitrary units, AU.; left heel, $14.4 \pm 8.3$ AU). TEWL remained acceptable at all sites in older patients despite the presence of dry skin (back, 7.1 $\pm 1.8 \mathrm{~g} / \mathrm{hm} 2 ;$ sacrum, $7.4 \pm 3.0$ $\mathrm{g} / \mathrm{hm} 2$; right heel, $17.7 \pm 7.1 \mathrm{~g} / \mathrm{hm} 2$; left heel, $19.4 \pm 8.1 \mathrm{~g} / \mathrm{hm} 2)$. Back $(0.61 \pm 0.13 \mathrm{AU})$ and sacral $(0.67 \pm 0.11 \mathrm{AU})$ skin elasticity and sacral skin thickness $(0.97 \pm 0.56 \mathrm{~cm})$ were significantly lower than those of healthy young people $(0.86 \pm 0.04 \mathrm{AU}, 0.87 \pm 0.05 \mathrm{AU}$, and $2.27 \pm 0.84$ $\mathrm{cm}$, respectively; $\mathrm{p}<.001$ for all sites). Moderate positive correlations were observed between back skin elasticity and serum albumin level ( $\mathrm{r}$ $=.445, \mathrm{p}<.001)$, and between sacral skin thickness and BMI $(r=.506, p<.001)$ in older patients.

Conclusions: Older patients have a lower epidermal water content and skin elasticity and thickness but not higher TEWL at sites predisposed to pressure ulcers. Moderate correlations were found between skin characteristics and demographic/laboratory data.

\section{Background}

The prevalence rate of pressure ulcers in all facilities in the United States was reported to have decreased from $13.5 \%$ in 2006 to $9.3 \%$ in 2015 [1]. In Japan, the prevalence rate in medical facilities ranged from $0.96-8.32 \%$ in 2006 [2] and from $0.77-2.46 \%$ in 2016 [3]. Thus, medical facilities in Japan have also succeeded in lowering the prevalence rate of pressure ulcers. However, the fact that that more than half of the patients with pressure ulcers are over 65 years old remains a challenge [3]. In addition, high treatment costs and lower quality of life due to pressure ulcers are important public health issues. In a previous survey conducted in a Japanese rural area in 2016, most patients with pressure ulcers were older and had age-related diseases and malnutrition [4]. It is important to not only assess properly the risk of pressure ulcers but also to provide prophylactic care for older patients.

The skin of older people tends to become vulnerable due to physical changes caused by aging, such as thinning of dermal and subcutaneous tissues and reduced resiliency and elasticity [5-7]. Owing to morphological and physiological changes, an external force applied to the skin surface easily induces a large force inside the skin, resulting in tissue distortion and ischemia [8]. The decrease in the number of sweat and sebaceous glands associated with decreased activity leads to the reduction in sweat and sebum production leading to an increase in skin surface $\mathrm{pH}$ and in the vulnerability to bacterial pathogens [9]. The skin of older people with urinary and fecal incontinence is prone to developing dermatitis because of the increase in surface $\mathrm{pH}$, dry skin, and decreased immune function [10]. Prolonged contact with urine and feces increases the water content in the stratum corneum, which makes the macerated skin more susceptible to pathogens, irritants, and enzymes [8]. Such damages to the skin contribute to pressure ulcer formation due to increased friction and shear forces on the skin [8].

Skin condition may be measured by skin physiological indices using noninvasive devices. Previous studies have assessed skin physiological indices in subjects of various ages and at various sites [11-17]. These values, however, were not always measured at common sites of pressure ulcers in high-risk older patients. The present study aimed to clarify physiological skin characteristics at common pressure ulcer sites in older Japanese patients, to compare the physiological skin indices between older patients and healthy young people, and to examine the relationship between skin physiological indexes and demographic/laboratory data in older patients.

\section{Methods}

\section{Patients and settings}

\section{Older patients}


The cross-sectional study was performed between October 2017 and August 2018 and recruited patients from a long-term care facility, equipped with 200 beds, providing care to rural residents of Kochi prefecture, Japan. This facility provides care to prevent pressure ulcers in accordance with the facility's policy consisting of guidelines for skin and continence care, regular turning and repositioning of the supporting surface mat on the bed to reduce pressure, and consultation with a nutritionist for bedridden patients. Patients without skin disorders, aged $\geq 60$ years, and with a cumulative Braden Scale score $\leq 18$ [18] were included. Patients with unstable physical condition were excluded to avoid the physical stress caused by maintaining the same body position during the observation. Patients who met the inclusion criteria were identified and recruited by hospital nurses unrelated to this study and trained in using the Braden Scale.

\section{Healthy young volunteers and ethics statement}

Twenty-five healthy female Japanese students of our university were voluntarily recruited for this study.

\section{Procedures}

For both older patients and healthy young people, the following six items were measured: epidermal water content; transepidermal water loss (TEWL) as a measure of the skin barrier function; and skin erythema, elasticity, surface temperature, and thickness. The four areas observed for the abovementioned items included the sacrum and the two heels as predisposed sites of pressure ulcers and the mid-to-lower back as the control site. Participants were placed in a lateral position and the measurement sites were identified by manual palpation. The authors confirmed that no skin care product was applied to the skin before the measurements. Noninvasive devices were used to measure each item. To avoid any possible effects on the measurement values caused by devices touching the skin, the skin surface temperature was measured first, followed by skin erythema, epidermal water content, TEWL, skin elasticity, and skin thickness [13]. The measurements using devices were determined based on previous studies and the manufacturer's instructions. Skin surface temperature, skin color [19, 20], and epidermal water content values [21-23] were measured four times per site and the measured values were averaged. The average TEWL value obtained by the device was used [23]. Skin elasticity was measured three times per site and the values were averaged [24, 25]. Skin thickness was measured in the longitudinal and lateral directions at three sites, including the sacrum and both buttocks, and the smallest measurement was used. All skin thickness measurements were made with the probe positioned perpendicular to the skin without compressing the subcutaneous tissue, so that an accurate thickness value would be obtained [17]. Room temperature and humidity were maintained at $22-24{ }^{\circ} \mathrm{C}$ and $40-50 \%$, respectively. The rooms where the healthy young volunteers were measured were also kept at the same temperature and humidity ranges. The experiments were carried out in the afternoon to avoid any disturbance caused by the circadian rhythm. All participants underwent an adaptation period of at least 30 minutes before the measurements.

\section{Instruments used}

The THERMOFOCUS $\AA-P R O$ (Tecnimed Srl, Vedano Olona, Italy) was used to measure the skin surface temperature. This thermometer is a non-contact device with a measurement range of 1.0 to $55.0^{\circ} \mathrm{C}$ and a precision of $\pm 0.3^{\circ} \mathrm{C}$. The Corneometer ${ }^{\circledR C M} 825$ (Courage-Khazaka electronic $\mathrm{GmbH}$, Cologne, Germany) was used to measure epidermal water content. This measurement is shown as 0-120 arbitrary units (AU) with a precision of $\pm 0.3 \%[26,27]$. The upper body epidermal water content was classified as very dry, dry, and normal for values of < $50 \mathrm{AU}, 50-60 \mathrm{AU}$, and $>60 \mathrm{AU}$, respectively, while for the lower limb the corresponding values for the same classification were $<35 \mathrm{AU}, 35-$ $50 \mathrm{AU}$, and $>50 \mathrm{AU}$. The Tewameter®TM300 (Courage-Khazaka electronic GmbH, Cologne, Germany) was used to measure TEWL. This device measures the amount of evaporated water content from the surface of the skin ( $\left.\mathrm{g} / \mathrm{hm}^{2}\right)$ with a precision of $\pm 0.5 \mathrm{~g} / \mathrm{hm}^{2}$ [28]. TEWL values of $0-10,10-15,15-25,25-30$, and $>30 \mathrm{~g} / \mathrm{hm}^{2}$ indicate very good, good, normal, bad, and very bad conditions, respectively. The Mexameter ${ }^{\circledR} \mathrm{MX} 18$ (Courage-Khazaka electronic $\mathrm{GmbH}$, Cologne, Germany) was used to measure skin erythema. This device measures the hemoglobin content in the skin. Erythema values are expressed in 0-999 AU with a precision of $\pm 0.5 \%[19,20]$. Skin erythema values of 0 170, 170-330, 330-450, 450-570, and > 570 AU indicate no, minor, diffuse, high-degree, and extreme erythema, respectively. The Cutometer®MPA580 (Courage-Khazaka electronic $\mathrm{GmbH}$ ) was used to measure skin elasticity. This device has a 4-mm-diameter opening suction probe that pulls the target skin into the probe with a vacuum pressure, followed by a relaxation time; this cycle is repeated 10 times. The vertical skin deformation was measured and analyzed using the computer software associated with Cutometer®MPA580. Overall skin elasticity is expressed in 0-1.00 AU [29,30]. Skin thickness was measured using a small-sized ultrasound imaging system, Vscan Dual Probe ${ }^{\circledR}$ (GE Healthcare, Tokyo, Japan), which has an electronic sector probe for observing deep areas and a high frequency linear contact for observing shallow areas. The image of the measured thickness is then displayed on a monitor. Skin thickness was determined by the depth of the surface of highly echogenic cortical bone from the skin surface [17].

\section{Pressure ulcer risk variables}

Data related to pressure ulcer risk factors were collected from each patient's medical record and skin examination findings. The Braden Scale [18] was used to assess the patients' pressure ulcer risk. The Braden Scale consists of the following six subscales: sensory 
perception, activity, mobility, skin moisture, friction/shear, and nutrition. Each subscale is ranked from 1 to 4 , except for the friction/shear subscale, which is scored on a scale of 1 to 3 . Subscale scores are added to determine the cumulative score, which may range from 6 to 23. Based on the total score, the risk of pressure ulcer is categorized as follows: highest risk (<9), high risk (10-12), moderate risk (13-14), low risk (15-18), and minimal risk (>18). A cut-off score of $\leq 18$ indicates an increased risk for pressure ulcer development [18, 31]. The Mini Nutritional Assessment (MNA), which has been shown to be indirectly related to pressure ulcer occurrence among patients aged $\geq 65$ years, was used to assess patients' nutritional status [32,33]. The MNA consists of six items on food intake, weight loss, mobility, psychological stress or acute disease, neuropsychological problems, and body mass index (BMI) or calf circumference [33, 34]. Based on the total score, the nutritional status is categorized as follows: normal nutritional status (12-14), at risk of malnutrition (8-11), and malnourished (0-7).

For healthy young people, BMI was calculated as weight in kilograms divided by the squared height in meters $\left(\mathrm{kg} / \mathrm{m}^{2}\right)$.

\section{Statistical analysis}

Statistical analysis was performed using SPSS, version 25 (IBM, Armonk, New York). The Shapiro-Wilk test was used to determine the normality of data distribution for older patients and healthy young people. The Mann-Whitney $\mathrm{U}$ or independent t-test was then performed to compare the skin physiological indices between groups as appropriate. Similarly, to examine the relationship between skin physiological indices and pressure ulcer risk in older patients, Pearson's or Spearman's rank correlation coefficient was applied. Two-tailed tests were used and significance was set at $p<0.05$. After completing this study, post-hoc power analysis was performed using $G^{*}$ Power 3 (Heinrich-HeineUniversität, Dusseldorf, Germany) [35]. G*Power 3 calculated statistical power by using significance level, effect size, and sample size [36]. Effect size was caluculated using the degrees of freedom and the t-value in the case of independent t-tests, and using the Z-value and the number of subjects for the Mann-Whitney $U$ test.

\section{Results}

A total of 55 older patients and 25 healthy young people met the eligibility criteria and were recruited for the study. This was a convenience sample and both patients and controls were recruited during the study period. Elderly patients and healthy young people had a mean age of $82.4 \pm 9.8$ and $21.4 \pm 1.3$ years, respectively (Table 1). Elderly patients had a lower BMl than healthy young people $\left(19.7 \pm 3.6 \mathrm{~kg} / \mathrm{m}^{2} \mathrm{vs}\right.$.

$\left.23.0 \pm 3.7 \mathrm{~kg} / \mathrm{m}^{2}, \mathrm{p}<.001\right)$. The medical data and pressure ulcer risk of older patients are shown in Table 2. In older patients, the Braden and MNA scores were $12.3 \pm 3.2$ (range, 7-17) and $8.0 \pm 2.2$ points (range, 1-12 points), respectively. Older patients had a lower-than-normal serum albumin level $(3.4 \pm 0.5 \mathrm{~g} / \mathrm{dl})$.

Table 1

Demographic variables of older patients and healthy young people

\begin{tabular}{|llllllll|}
\hline Variable & Elderly patients $(\mathbf{n}=\mathbf{5 5})$ & Healthy young people $(\mathbf{n}=\mathbf{2 5})$ & $\mathbf{p}$ \\
\hline Sex & & & & & & & \\
\hline Women, $\mathrm{n}(\%)$ & 32 & $(58.2)$ & 25 & $(100.0)$ & \\
\hline Age (years; mean \pm SD) & 82.4 & \pm & 9.8 & 21.4 & \pm & 1.3 & $<.000^{\mathrm{a}}$ \\
\hline BMI $\left(\mathrm{kg} / \mathrm{m}^{2}\right.$; mean \pm SD) & 19.7 & \pm & 3.6 & 23.0 & \pm & 3.7 & $<.001^{\mathrm{a}}$ \\
\hline aMann-Whitney U test & & & & & & & \\
\hline SD, standard deviation; BMl, body mass index & & & & \\
\hline
\end{tabular}


Table 2

Medical data and pressure ulcer risk of older patients

\begin{tabular}{|c|c|c|c|c|c|c|}
\hline \multicolumn{7}{|l|}{ Variables } \\
\hline \multicolumn{7}{|l|}{ Diagnosis (multiple answers) } \\
\hline Neoplasms, n (\%) & 4 & \multicolumn{5}{|c|}{$(8.0)$} \\
\hline Endocrine, nutritional, and metabolic diseases, n (\%) & 12 & \multicolumn{5}{|c|}{$(24.0)$} \\
\hline Dementia in Alzheimer disease, $\mathrm{n}(\%)$ & 14 & \multicolumn{5}{|c|}{$(25.5)$} \\
\hline Extrapyramidal and movement disorders, n (\%) & 11 & \multicolumn{5}{|c|}{$(20.0)$} \\
\hline Heart diseases, n (\%) & 15 & \multicolumn{5}{|c|}{$(27.3)$} \\
\hline Cerebrovascular diseases, n (\%) & 38 & \multicolumn{5}{|c|}{$(69.1)$} \\
\hline Respiratory diseases, n (\%) & 12 & \multicolumn{5}{|c|}{$(21.8)$} \\
\hline \multicolumn{7}{|l|}{ Laboratory test } \\
\hline Albumin $(g / d l)^{a}$ & 3.4 & \pm & 0.5 & 2.1 & - & 4.2 \\
\hline Total protein $(\mathrm{g} / \mathrm{dl})^{\mathrm{a}}$ & 6.7 & \pm & 0.7 & 5.2 & - & 7.8 \\
\hline Red blood cell $\left(10^{6} / \mathrm{dl}\right)^{a}$ & 3.7 & \pm & 0.6 & 2.4 & - & 5.3 \\
\hline Hemoglobin $(\mathrm{g} / \mathrm{dl})^{a}$ & 11.7 & \pm & 2.1 & 7.4 & - & 17 \\
\hline Braden scale total score ${ }^{a}$ & 12.3 & \pm & 3.2 & 7.0 & - & 17.0 \\
\hline Mini Nutritional Assessment ${ }^{a}$ & 8.0 & \pm & 2.2 & 1.0 & - & 12.0 \\
\hline \multicolumn{7}{|l|}{ Pressure ulcer risk factors } \\
\hline Repositioning individuals in bed, unable, n (\%) & 38 & \multicolumn{5}{|c|}{$(69.1)$} \\
\hline Repositioning seated individuals, unable, n (\%) & 52 & \multicolumn{5}{|c|}{$(94.5)$} \\
\hline Bony prominence, yes, n (\%) & 16 & \multicolumn{5}{|c|}{$(29.1)$} \\
\hline Joint contracture, yes, n (\%) & 35 & \multicolumn{5}{|c|}{$(63.6)$} \\
\hline Urinary incontinence, yes, n (\%) & 50 & \multicolumn{5}{|c|}{$(90.9)$} \\
\hline Fecal incontinence, yes, $\mathrm{n}(\%)$ & 43 & \multicolumn{5}{|c|}{$(78.2)$} \\
\hline Edema, yes, n (\%) & 24 & \multicolumn{5}{|c|}{$(43.6)$} \\
\hline \multicolumn{7}{|l|}{ 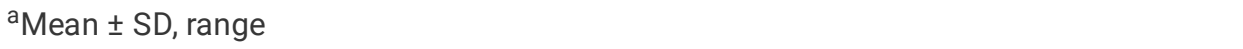 } \\
\hline SD, standard deviation & & & & & & \\
\hline
\end{tabular}

Regarding the presence of pressure ulcer risk factors in older patients, 38 patients were unable to reposition themselves in the bed (69.1\%), 50 patients had urinary incontinence $(90.9 \%)$, and 43 patients had fecal incontinence $(78.2 \%)$.

The comparison of the 6 skin physiological indices between older patients and healthy young people is shown in Table 3 . Skin temperature was significantly higher in older patients at all sites (back, $34.8^{\circ} \mathrm{C} \pm 0.9{ }^{\circ} \mathrm{C}$; sacrum, $34.9^{\circ} \mathrm{C} \pm 0.8^{\circ} \mathrm{C}$; right heel, $29.7{ }^{\circ} \mathrm{C} \pm 3.2{ }^{\circ} \mathrm{C}$; left heel, $29.7^{\circ} \mathrm{C} \pm 3.2^{\circ} \mathrm{C}$ ) than in healthy young people (back, $33.7^{\circ} \mathrm{C} \pm 1.0^{\circ} \mathrm{C}$; sacral, $33.1^{\circ} \mathrm{C} \pm 1.2^{\circ} \mathrm{C}$; right heel, $25.9^{\circ} \mathrm{C} \pm 2.6^{\circ} \mathrm{C}$; left heel, $25.8^{\circ} \mathrm{C} \pm$ $\left.2.5^{\circ} \mathrm{C}\right)(\mathrm{p}<.001$ for all sites). Epidermal water content at the sacrum was significantly higher in older patients than in healthy young people $(31.1 \pm 10.5$ vs. $26.3 \pm 6.4 \mathrm{AU}, \mathrm{p}=.025)$. Conversely, in the right and left heels, the epidermal water content was lower in older patients than in healthy young people (right heel, $14.8 \pm 9.1 \mathrm{AU}$; left heel, $14.4 \pm 8.3 \mathrm{AU}$ vs. right heel, $23.2 \pm 10.9 \mathrm{AU}$; left heel, $20.6 \pm 9.0 \mathrm{AU}$; $\mathrm{p}<.001 \mathrm{and}$ .003 for the right and left heel, respectively). The epidermal water content was classified as very dry at all sites in both older patients and healthy young people. TEWL values were significantly lower at all sites in older patients (back, $7.1 \pm 1.8 \mathrm{~g} / \mathrm{hm}^{2} ; \mathrm{sacral}, 7.4 \pm 3.0 \mathrm{~g} / \mathrm{hm}{ }^{2} ; \mathrm{right}$ heel, $17.7 \pm 7.1 \mathrm{~g} / \mathrm{hm}^{2}$; left heel, $19.4 \pm 8.1 \mathrm{~g} / \mathrm{hm}^{2}$ ) than in healthy young people (back, $11.9 \pm 7.9 \mathrm{~g} / \mathrm{hm}^{2} ; \mathrm{sacral}, 9.4 \pm 2.9 \mathrm{~g} / \mathrm{hm}^{2} ;$ right heel, $31.0 \pm 9.9 \mathrm{~g} / \mathrm{hm}^{2}$; left heel, $\left.30.8 \pm 8.1 \mathrm{~g} / \mathrm{hm}^{2}\right)$ ( $\mathrm{p}<.001$ for all sites). In both older patients and healthy young people, the TEWL was 
classified as very good or good at the sacrum and back. However, in both heels, the TEWL values were normal in older patients and bad in healthy young people. Skin erythema values were significantly higher at the back and sacrum in older patients (back, $225.2 \pm 67.2 \mathrm{AU}$;

sacrum, $264.3 \pm 81.2 \mathrm{AU}$ ) than in healthy young people (back, $172.0 \pm 32.4$ a.u.; sacrum, $188.6 \pm 26.8$ a.u.) ( $p<.001$ for both areas). In both older patients and healthy young people, skin erythema was classified as minor at all sites. Skin elasticity was significantly lower at the back and sacrum in older patients (back, $0.61 \pm 0.13$; sacrum, $0.67 \pm 0.11$ ) than in healthy young people (back, $0.86 \pm 0.04$; sacrum, $0.87 \pm$ $0.05)$ ( $p<.001$ for both areas). The sacral and right heel skin was significantly thinner in older patients (sacrum, $0.97 \pm 0.56 \mathrm{~cm} ;$ right heel, $0.95 \pm 0.24 \mathrm{~cm}$ ) than in healthy young people (sacrum, $2.27 \pm 0.84 \mathrm{~cm}$; right heel, $1.02 \pm 0.15 \mathrm{~cm})(p<.001 \mathrm{for}$ the sacrum and $p=.037$ for the right heel). 
Table 3

Comparisons of skin physiological indices between older patients and healthy young people

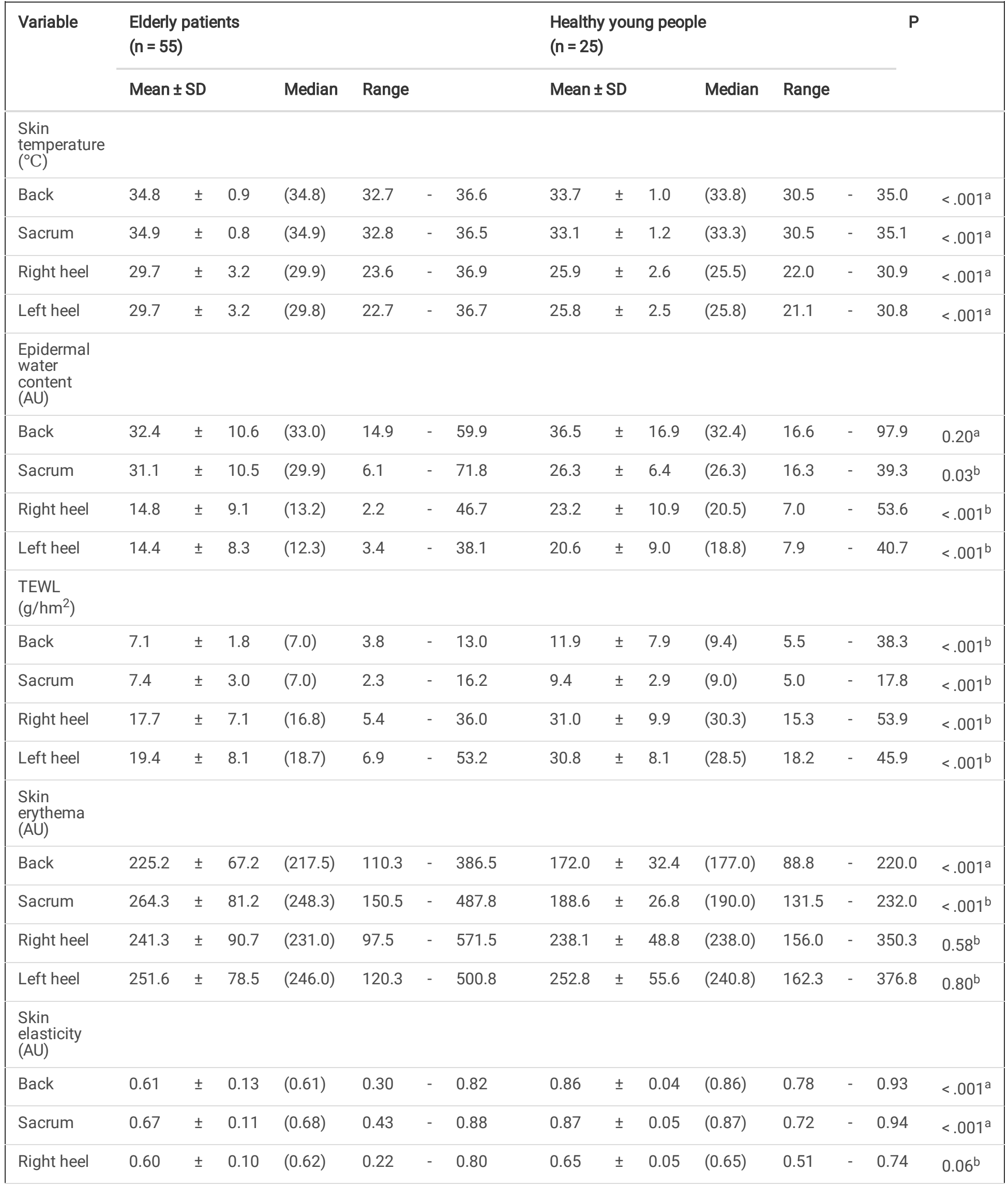

aIndependent t-test; ${ }^{b}$ Mann-Whitney $\mathrm{U}$ test. AU, arbitrary units, TEWL, transepidermal water loss 


\begin{tabular}{|c|c|c|c|c|c|c|c|c|c|c|c|c|c|c|c|}
\hline \multirow{3}{*}{$\begin{array}{l}\text { Variable } \\
\text { Left heel }\end{array}$} & \multicolumn{7}{|c|}{$\begin{array}{l}\text { Elderly patients } \\
(n=55)\end{array}$} & \multicolumn{7}{|c|}{$\begin{array}{l}\text { Healthy young people } \\
(n=25)\end{array}$} & \\
\hline & \multicolumn{3}{|c|}{ Mean \pm SD } & \multirow{2}{*}{$\begin{array}{l}\text { Median } \\
(0.63)\end{array}$} & \multicolumn{3}{|c|}{ Range } & \multicolumn{3}{|c|}{ Mean \pm SD } & \multirow{2}{*}{$\begin{array}{l}\text { Median } \\
(0.64)\end{array}$} & \multicolumn{2}{|l|}{ Range } & \multirow[b]{2}{*}{0.73} & \\
\hline & 0.63 & \pm & 0.08 & & 0.48 & - & 0.83 & 0.63 & \pm & 0.05 & & 0.50 & - & & $0.96^{a}$ \\
\hline \multicolumn{16}{|l|}{$\begin{array}{l}\text { Skin } \\
\text { thickness } \\
(\mathrm{cm})\end{array}$} \\
\hline Sacral & 0.97 & \pm & 0.56 & $(0.78)$ & 0.30 & - & 2.93 & 2.27 & \pm & 0.84 & $(2.1)$ & 0.80 & - & 4.41 & $<.001^{b}$ \\
\hline Right heel & 0.95 & \pm & 0.24 & $(0.93)$ & 0.60 & - & 1.80 & 1.02 & \pm & 0.15 & $(1.0)$ & 0.67 & - & 1.25 & $<.001^{\mathrm{b}}$ \\
\hline Left heel & 0.95 & \pm & 0.27 & $(0.91)$ & 0.53 & - & 1.95 & 0.98 & \pm & 0.14 & $(1.0)$ & 0.71 & - & 1.28 & $0.47^{\mathrm{b}}$ \\
\hline
\end{tabular}

In older patients, the relationship between demographic and laboratory data and skin physiological indices was examined (data not shown). A moderate negative correlation was observed between heel skin temperature and age (right heel, $r=-.451, p<.001$; left heel, $r=$ $-.541, p<.001)$. Skin temperature and BMI showed a weak negative correlation at the back and sacrum (back, $r=-.394, p=.003 ;$ sacrum, $r$ $=-.382, p=.005)$. Weak positive correlations were observed between sacral erythema and age $(r=.319, p=.025)$ and between sacral erythema and total protein level $(r=-.311, p=.025)$. Moderate and weak positive correlations were observed between back $(r=.445, p$ $<.001)$ and sacral $(r=.273, p<.045)$ skin elasticity and serum albumin levels, respectively. On the contrary, there was a weak negative correlation between back skin elasticity and age $(r=-.355, p=.009)$. Skin thickness and BMI showed a moderately positive correlation at all sites (sacrum, $r=.506, p<.001$; right heel, $r=.482, p<.001$; left heel, $r=.460, p<.001$ ). Finally, sacral skin thickness and serum albumin level showed a weak positive correlation $(r=.282, p=.041)$. No other correlations were observed.

The statistical power of the significant differences in skin elasticity and thickness was high (skin elasticity: back, .92; sacrum, .90; sacral skin thickness: .76). The statistical power of the moderate correlations between skin physiological indices and pressure ulcer risk in older patients ranged from .94 to .99 .

\section{Discussion}

The aim of this study was to evaluate the skin physiological indexes at sites predisposed to pressure ulcers in older Japanese patients. The epidermal water content indicated the presence of very dry skin in older patients, especially at both heels. The skin barrier function of older patients was in a relatively good condition, as shown by the TEWL values. However, back and sacral skin elasticity, as well as sacral skin thickness, were significantly worse in older patients than in healthy young people. The back skin elasticity was positively correlated with serum albumin level in older patients. Skin thickness at all sites was positively correlated with BMI.

\section{Skin surface temperature}

The skin surface temperature was significantly higher in older patients than in healthy young people at all sites. The older patients' back, sacral, and heel skin surface temperature in this study was also higher than that of healthy middle-aged individuals in a previous study [14]. Most older patients in this study were bedridden and covered with blankets for a long time; differences in skin surface temperature between older patients and healthy young people may have therefore been influenced by their living environment.

\section{Epidermal water content}

In both older patients and healthy young people, the epidermal water content at all sites was lower than the reference value of $50 \mathrm{AU}$, indicating very dry skin. Particularly in older patients, the epidermal water content at both heels was extremely low. There were no correlations between epidermal water content at all sites and age, BMI, and laboratory test parameters in older patients. In previous studies of intensive care unit patients, He et al. [15] found that a lower epidermal water content was a risk factor for pressure ulcers. Conversely, Sanada et al. [37] found that a higher epidermal water content was associated with increased occurrence of pressure ulcers. Vulnerable skin conditions such as excessive dryness or wetness increase friction and shear, resulting in injuries to the skin and subcutaneous tissue. Skin dryness in older patients, especially at the heels, might contribute to the high risk of pressure ulcer formation. 


\section{TEWL}

Given that the TEWL increases when the skin becomes dry due to the lack of intercellular lipids, TEWL is the most reliable indicator of the skin barrier function. Older patients in this study showed acceptable TEWL despite their skin being very dry. On the other hand, healthy young people had good or very good TEWL at the back and sacrum, whereas at both heels TEWL was classified as very bad. It has been reported that TEWL at the palm, sole, and forehead is relatively high because of the activity of eccrine sweat glands [12, 14]. The high TEWL level at both heels in the healthy young people may not indicate decreased skin barrier function; instead, it may be associated to the agedependent hyperhidrotic function.

\section{Skin erythema}

Back and sacral skin erythema values were significantly higher in older patients than in healthy young people. Nevertheless, skin erythema was evaluated as minor in all sites for both older patients and healthy young people. Previous studies showed that Iranians' back skin erythema level was $331.94 \pm 62.23 \mathrm{AU}$ [12], while the sacral erythema of a Swiss sample was 163.2 $\pm 48.3 \mathrm{AU}$ [13], indicating that the skin color differs among different races $[14,38]$. We believe that the "minor erythema" measured in this study might be an overestimation related to the Mongolian skin color. Most older patients in this study had urinary and fecal incontinence. Nevertheless, we could not determine whether the higher level of skin erythema (>200 AU) in older patients was a sign of inflammation or stasis. However, we believe that the minor erythema at the predisposed sites seen in older patients may be a race-dependent phenomenon.

\section{Skin elasticity}

Skin elasticity values at the back and sacral areas in older patients were significantly lower than those in healthy young people. Another study also found that older people had lower skin elasticity than young people [39]. Both reduction of collagen synthesis and degeneration of the extracellular matrix occur in an age-dependent manner, leading to decreased skin elasticity [7]. In this study, a moderate positive correlation between back skin elasticity and serum albumin level and a weak positive correlation between sacral skin elasticity and serum albumin level were found. In older patients, skin elasticity might be affected by the serum albumin level in addition to aging.

\section{Skin thickness}

Sacral skin thickness was found to be significantly lower in older patients than in healthy young people. The decreasing number of fibroblasts seen with aging causes reduction of the collagen and proteoglycan content in the dermis as well as atrophy of fat cells in the subcutaneous tissue. As a result, thinning of the dermis and subcutaneous tissue occurs in older people. Additionally, a moderate positive correlation between sacral skin thickness and BMI was observed. In accordance with this study's findings, Schubert et al. [40] demonstrated that older patients with pressure ulcers had skin thinning at the sacral area and lower BMI. Therefore, skin thinning in the predisposed sites in older patients is an important parameter for evaluating pressure ulcer risk. BMI is a well-known nutritional index; skin thickness can easily be indirectly evaluated by calculating the BMI. A significant difference in skin thickness between older patients and healthy young people was detected at the right but not at the left heel. Heel skin thickness was measured from the calcaneal bone surface to the skin surface; adipose tissue thickness around the calcaneus is thought to have a minor relation to total body fat. Nevertheless, the authors believe that the skin thickness at both heels in high-risk older patients was affected by neither aging nor BMI.

\section{Limitations}

This study is limited by its small sample size, single-center cross-sectional design, and the predominance of female participants due to convenience sampling. Therefore, it is difficult to generalize the study findings. In the future, larger multi-center and sex-balanced studies are needed. In addition, this study was performed between October and August; hence, variations in climate during this period may have influenced the measurements of skin surface temperature, epidermal water content, and TEWL.

\section{Implications for clinical practice}

This study determined the parameters, from those listed in several guidelines, that should be monitored in older patients at a high risk of developing pressure ulcers [41]. For evaluating pressure ulcer risks at the sacral region, it is important to assess the patients' nutritional status, especially the BMI value, and skin thickness. Skin moisturizing should also be incorporated in the routine care of older patients.

\section{Conclusion}

The characteristics of the 4 sites predisposed to pressure ulcers were as follows: reduced epidermal water content in the heels, decreased back and sacral skin elasticity, and reduced skin thickness in the sacrum. Skin temperature and TEWL remained within acceptable values even in older bedridden patients at a high risk of developing pressure ulcers. 


\section{Abbreviations}

$\mathrm{AU}$

arbitrary units

BMI

body mass index

MNA

Mini Nutritional Assessment

TEWL

transepidermal water loss

\section{Declarations}

\section{Ethics approval and consent to participate}

The study procedures were approved by the research ethics committees of the University of Kochi and Shiragikuen Hospital (Approval Number: 17-7 and 17-43) and adhered to the guidelines stipulated in the Declaration of Helsinki. All individuals involved in this study provided their written informed consent.

\section{Consent for publication}

All patients provided publishing consent.

\section{Availability of data and materials}

The datasets analyzed during the current study are available from the corresponding author on reasonable request.

\section{Competing interests}

The authors declare that they have no competing interests

\section{Funding}

The design of the study and collection, analysis, and interpretation of data and writing the manuscript were supported by JSPS KAKENHI Grant Number JP 15K11813 (received by Mitsunori Ikeda) and 16K12263 (received by Hiroko Takeshima Kohara).

\section{Acknowledgements}

The authors would like to express gratitude to all participants for their contribution to this research and the staff in Shiragikuen Hospital, Tosa, Kochi, Japan for facilitating this study. The authors would like to thank Editage (www.editage.com) for English language editing.

\section{References}

1. VanGilder C, Lachenbruch C, Algrim-Boyle C, Meyer S. The International Pressure Ulcer Prevalence ${ }^{\text {TM }}$ Survey: 2006-2015: A 10-Year Pressure Injury Prevalence and Demographic Trend Analysis by Care Setting. J Wound Ostomy Continence Nurs. 2017;44:20-8.

2. Sugama J, Shido K, Ishikawa O, Sanada H, Sato A, Kaitani T, et al. Pressure ulcer prevalence by treatment location and site / severity (depth) of pressure ulcer. Jpn J P U. 2008;10:153-61. [Japanese]

3. Konya C, Shido K, Abe M, Abe Y, lizaka S, Shimada K, et al. Prevalence of self-weight-related pressure ulcers by treatment location, characteristics of affected persons, site / importance, and care and local management. Jpn J P U. 2018;20:446-85. [Japanese]

4. Kohara H, Ikeda M, Inoue M, Morishita S. A survey of home care patients suffering from pressure ulcer in Kochi. J K W U Acad Nurs. 2017;42:62-70. [Japanese]

5. Farage MA, Miller KW, Berardesca E, Maibach HI. Clinical implications of aging skin: cutaneous disorders in the older. Am J Clin Dermatol. 2009;10:73-86.

6. Archer DF. Postmenopausal skin and estrogen. Gynecol Endocrinol. 2012;28:2-6.

7. Yaar M. Clinical and Histological Features of Intrinsic versus Extrinsic Skin Aging. In: Barbara A. Gilchrest, Krutmann J, editors. Skin aging. $1^{\text {st }}$ ed. Heidelberg: Springer; 2006. p. 198. 
8. Doughty DB, McNichol LL. General Concepts Related to Skin and Soft Tissue Injury Caused by Mechanical Factors. In: Doughty DB, McNichol LL, editors. Wound, Ostomy and Continence Nurses Society® Core Curriculum: Wound Management. 1st ed. Philadelphia: Wolters Kluwer; 2015. p. 273-9.

9. Chang AL, Wong JW, Endo JO, Norman RA. Geriatric dermatology review: Major changes in skin function in older patients and their contribution to common clinical challenges. J Am Med Dir Assoc. 2013;14:724-30.

10. Kottner J, Beeckman D. Incontinence-associated dermatitis and pressure ulcers in geriatric patients. G Ital Dermatol Venereol. 2015;150:717-29.

11. 11. Fiedler M, Gerhardt LC, Derler S, Bischofberger G, Hürny C, Münzer T. Assessment of biophysical skin properties at different body sites in hospitalized old patients: results of a pilot study. Gerontology. 2012;58:513-7.

12. 12. Firooz A, Sadr B, Babakoohi S, Sarraf-Yazdy M, Fanian F, Kazerouni-Timsar A, et al. Variation of biophysical parameters of the skin with age, gender, and body region. ScientificWorldJournal. 2012;2012:386936.

13. 13. Scheel-Sailer A, Frotzler A, Mueller G, Annaheim S, Rossi RM, Derler S. Challenges to measure hydration, redness, elasticity and perfusion in the unloaded sacral region of healthy persons after supine position. J Tissue Viability. 2015;24:62-70.

14. 14. Kleesz P, Darlenski R, Fluhr JW. Full-body skin mapping for six biophysical parameters: baseline values at 16 anatomical sites in 125 human subjects. Skin Pharmacol Physiol. 2012;25:25-33.

15. 15. He M, Tang A, Ge X, Zheng J. Pressure Ulcers in the Intensive Care Unit: An Analysis of Skin Barrier Risk Factors. Adv Skin Wound Care. 2016;29:493-8.

16. 16. Yusuf S, Okuwa M, Shigeta Y, Dai M, luchi T, Rahman S, et al. Microclimate and development of pressure ulcers and superficial skin changes. Int Wound J. 2015;12:40-6.

17. 17. Yalcin E, Akyuz M, Onder B, Unalan H, Degirmenci I. Skin thickness on bony prominences measured by ultrasonography in patients with spinal cord injury. J Spinal Cord Med. 2013;36:225-30.

18. 18. Bergstrom N, Braden BJ, Laguzza A, Holman V. The Braden Scale for Predicting Pressure Sore Risk. Nurs Res. 1987;36:205-10.

19. 19. Shin JW, Lee DH, Choi SY, Na JI, Park KC, Youn SW et al. Objective and non-invasive evaluation of photorejuvenation effect with intense pulsed light treatment in Asian skin. J Eur Acad Dermatol Venereol. 2011;25:516-22.

20. 20. Clarys $P$, Alewaeters K, Lambrecht R, Barel AO. Skin color measurements: comparison between three instruments: the Chromameter(R), the DermaSpectrometer(R) and the Mexameter(R). Skin Res Technol. 2000;6:230-8.

21. 21. Wendling P-A, Dell'Acqua G. Skin biophysical properties of a population living in Valais, Switzerland. Skin Res Technol. 2003;9:3318.

22. 22. Nakagami G, Sanada H, Konya C, Kitagawa A, Tadaka E, Matsuyama Y. Evaluation of a new pressure ulcer preventive dressing containing ceramide 2 with low frictional outer layer. J Adv Nurs. 2007;59:520-9.

23. 23. Bornkessel A, Flach M, Arens-Corell M, Elsner P, Fluhr JW. Functional assessment of a washing emulsion for sensitive skin: mild impairment of stratum corneum hydration, $\mathrm{pH}$, barrier function, lipid content, integrity and cohesion in a controlled washing test. Skin Res Technol. 2005;11:53-60.

24. 24. lizaka S, Minematsu T, Oba M, Akase T, Sanada H, Sugama J. Skin function in overweight individuals and the effect of weight reduction. J Jpn WOCM. 2011;14:258-65. [Japanese]

25. 25. lizaka S, Sanada H, Abe M, Tanaka H. Development and validation of a tool for community-based screening for skin frailty in the older. J Jpn WOCM. 2018;22:287-96. [Japanese]

26. 26. Heinrich U, Koop U, Leneveu-Duchemin MC, Osterrieder K, Bielfeldt S, Chkarnat C, et al. Multicentre comparison of skin hydration in terms of physical-, physiological- and product-dependent parameters by the capacitive method (Corneometer CM 825). Int J Cosmet Sci. 2003;25:45-53.

27. 27. Berardesca E. EEMCO guidance for the assessment of stratum corneum hydration: electrical methods. Skin Res Technol. 1997;3:126-32.

28. 28. Barel AO, Clarys P. Study of the stratum corneum barrier function by transepidermal water loss measurements: comparison between two commercial instruments: Evaporimeter and Tewameter. Skin Pharmacol. 1995;8:186-95.

29. 29. Gerhardt LC, Lenz A, Spencer ND, Münzer T, Derler S. Skin-textile friction and skin elasticity in young and aged persons. Skin Res Technol. 2009;15:288-98.

30. 30. Everett JS, Sommers MS. Skin viscoelasticity: physiologic mechanisms, measurement issues, and application to nursing science. Biol Res Nurs. 2013;15:338-46.

31. 31. Ayello EA, Braden B. How and why to do pressure ulcer risk assessment. Adv Skin Wound Care. 2002;15:125-31.

Page $11 / 12$ 
32. 32. Kagansky N, Berner Y, Koren-Morag N, Perelman L, Knobler H, Levy S. Poor nutritional habits are predictors of poor outcome in very old hospitalized patients. Am J Clin Nutr. 2005;82:784-91.

33. 33. Yatabe MS, Taguchi F, Ishida I, Sato A, Kameda T, Ueno S, et al. Mini nutritional assessment as a useful method of predicting the development of pressure ulcers in older inpatients. J Am Geriatr Soc. 2013;61:1698-704.

34. 34. Vellas B, Villars H, Abellan G, Soto ME, Rolland Y, Guigoz Y, et al. Overview of the MNA-Its history and challenges. J Nutr Health Aging. 2006;10:456-63.

35. Faul F, Erdfelder E, Lang A-G, Buchner A. G*Power 3: A flexible statistical power analysis program for the social, behavioral, and biomedical sciences. Behav Res Methods. 2007;39:175-191.

36. Faul F, Erdfelder E, Buchner A, Lang A-G. Statistical power analyses using G*Power 3.1: Tests for correlation and regression analyses. Behav Res Methods. 2009;41:1149-1160.

37. Sanada H, Sugama J, Kitagawa A, Thigpen B, Kinosita S, Murayama S. Risk factors in the development of pressure ulcers in an intensive care unit in Pontianak, Indonesia. Int Wound J. 2007;4:208-15.

38. Fullerton A, Fischer T, Lahti A, Wilhelm KP, Takiwaki H, Serup J. Guidelines for measurement of skin colour and erythema. A report from the Standardization Group of the European Society of Contact Dermatitis. Contact Dermatitis. 1996;35:1-10.

39. 39. Ryu HS, Joo YH, Kim SO, Park KC, Youn SW. Influence of age and regional differences on skin elasticity as measured by the Cutometer. Skin Res Technol. 2008;14:354-8.

40. 40. Schubert V, Ohlsson K, Stevens U. Reduced tissue thickness over the sacrum as a risk factor for pressure sores. J Tissue Viability. 1992;2:82-6.

41. 41. National Pressure Ulcer Advisory Panel, European Pressure Ulcer Advisory Panel and Pan Pacific Pressure Injury Alliance. Prevention and Treatment of Pressure Ulcers: Quick Reference Guide.: Osborne Park: Cambridge Media; 2014. 